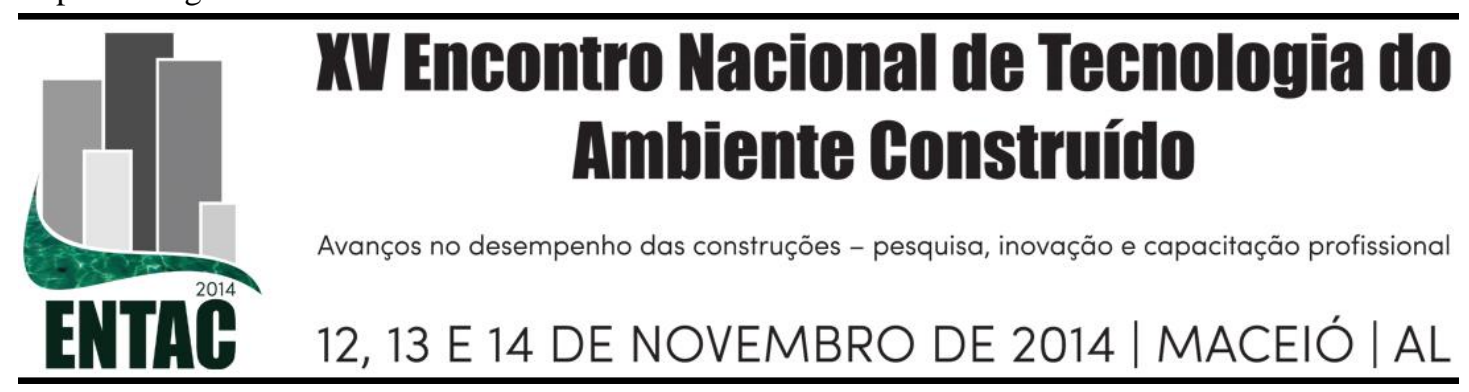

\title{
ANÁLISE DO DESEMPENHO TÉRMICO DE ENVOLTÓRIAS EM CONCRETO NO BRASIL
}

\section{OLIVEIRA, Raquel Diniz (1); VILELA, Carolina Tavares de Sousa (2); SOUZA, Roberta Vieira Gonçalves (3); SILVA, Roberto Márcio (4) \\ (1) Laboratório de Conforto Ambiental e Eficiência Energética em Edificações} (LABCON) da Escola de Arquitetura (EA) da Universidade Federal de Minas Gerais (UFMG), 31 3409-8825, e-mail: raqueldo@gmail.com, (2) LABCON da EAUFMG, email: caroltsv@gmail.com, (3) LABCON da EAUFMG, e-mail: robertavgs2@gmail.com, (4) Departamento de Engenharia de Estruturas da Escola de Engenharia da UFMG, e-mail: roberto@dees.ufmg.br

\section{RESUMO}

O mercado da construção civil precisou adotar sistemas mais rápidos para produzir moradias seriadas em reposição ao déficit habitacional brasileiro. Contudo, os mesmos sistemas construtivos têm sido utilizados de forma semelhante em todo Brasil, independentemente do clima ou outras questões regionais. O objetivo deste estudo consiste no diagnóstico do desempenho térmico da envoltória de habitação multifamiliar em concreto para as oito Zonas Bioclimáticas brasileiras. Para tanto, será analisado um protótipo do sistema construtivo em concreto pelos métodos prescritivos das normas nacionais. Foram considerados os requisitos relativos ao desempenho térmico das normas NBR 15.220 e 15.575 da Associação Brasileira de Normas Técnicas (ABNT) e também do Regulamento Técnico da Qualidade para o Nível de Eficiência Energética de Edificações Residenciais (RTQ-R) e Selo Casa Azul, bem como a eficiência do edifício para verão e inverno pelo RTQ-R. Selecionou-se uma edificação com paredes e lajes maciças de concreto e telha de fibrocimento. Analisaram-se, ainda, variações do projeto adicionando-se isolamento na cobertura e alterando-se a área de ventilação. Verificou-se que os valores limites indicados são distintos em cada norma o que evidencia falta de uniformização na legislação brasileira. Por outro lado, todas as prescrições apontaram a necessidade de isolamento térmico para a parede de concreto. Já cobertura dispensa este recurso caso possua cores claras. Quanto aos resultados do RTQ-R, infere-se que a melhoria da transmitância da cobertura foi suficiente para aumentar a eficiência da envoltória no verão, exceto para a zona bioclimática 2 . Em suma, as paredes de concreto compõem um sistema construtivo recente e em crescimento no Brasil que necessita de verificação do impacto térmico da sua adoção seriada. Este estudo propõe-se colaborar, portanto, com esta demanda.

Palavras-chave: normas brasileiras, envoltória de concreto, desempenho térmico. 


\begin{abstract}
The construction market started to adopt faster and serial systems to reduce the Brazilian housing deficit. However, so the same constructive systems are used similarly throughout the country, regardless the local climate. This paper aims to diagnose the thermal performance envelopment of a multifamily dwelling for the Brazilian Bioclimatic zones. For this, it considers a building prototype on concrete, tested using the prescriptive methods of Brazilian standards. The requirements of NBR 15.220, NBR 15.575, RTQ - R and Blue House Label, about thermal performance and building efficiency for summer and winter for the $R T Q-R$ were considered. It was selected a building with walls and slabs on concrete and fiber cement roof. It also analyzed projects variations on insulation for the roof and ventilation opening areas. Results showed that the limit values are different for each standard, which highlights the necessity of uniform the requirements. Furthermore, all the prescriptions indicated that is necessary thermal insulation for the concrete wall. There is no needing insulate light colors roofs. For RTQ -R, it can be inferred that the improvement of roof transmittance was enough to increase the envelope efficiency in the summer, except for zone 2. In sum, the concrete wall is a growing system in Brazil that requires verification of the thermal impact of its serial adoption. This study aims, collaborate with this demand.
\end{abstract}

Keywords: Brazilian standards, concrete envelopment, thermal performance.

\title{
1 INTRODUÇÃO
}

Segundo dados da Pesquisa Nacional de Amostra por Domicílios - Pnad, de 2008, estimase um déficit de 5,5 milhões de moradias (BRASIL - Ministérios das Cidades, 2008, p.8891). Tal fato alavancou a criação de novos programas governamentais bem como a adoção de sistemas construtivos mais rápidos para a redução deste déficit. Neste sentido, cresce a utilização das paredes de concreto maciças em razão da velocidade de execução em relação àqueles tradicionais. Neste sistema a estrutura e a vedação são moldadas "in loco" numa única etapa de concretagem permitindo maior racionalização, produtividade, redução de prazos, material e mão de obra (MELHADO, p.4, 1998).

Contudo, acredita-se que este sistema construtivo necessite de modificações para atender as prescrições mínimas referentes ao desempenho térmico de edifícios. No Brasil têm-se quatro instrumentos normativos em vigor que abordam o tema: a NBR 15.220 (2005), a NBR 15.575 (2013), o Selo Casa Azul (2010) e o RTQ-R (2012). A primeira norma citada refere-se a habitações unifamiliares de interesse social com até três pavimentos além de estabelecer o zoneamento bioclimático brasileiro bem como as diretrizes construtivas específicas para cada zona (ABNT, 2005). A segunda NBR, criada em 2008 e em vigor desde julho de 2013, estabelece desempenho mínimo para novas habitações quanto ao quesito térmico, acústico, lumínico, estrutural, de segurança contra incêndio, durabilidade (vida útil de materiais e estruturas), entre outros (ABNT, 2013). No âmbito do Programa Brasileiro de Etiquetagem PBE EDIFICA tem-se o RTQ-R, instituído pelo Inmetro em 2010 e atualizado em 2012. Tal regulamento estabelece métodos para avaliação e etiquetagem voluntária de habitações. A classificação alcançada pela edificação é atestada por meio da Etiqueta Nacional de Conservação da Energia (ENCE), a qual informa seu desempenho energético avaliado por requisitos de eficiência que variam de A (mais eficiente) a $\mathrm{E}$ (menos eficiente). Atribui-se para cada requisito um peso e o edifício será classificado de acordo com a sua pontuação final podendo obter pontos extras por bonificações (BRASIL, 2012). 
Já o Selo Casa Azul da Caixa Econômica Federal tem por escopo atestar o caráter sustentável de construções habitacionais de interesse social apresentadas em processos de financiamento ou incluídas em programas de repasse imobiliário. A adesão ao processo de certificação é voluntária. Têm-se três categorias variando da básica à superior (Bronze, Prata e Ouro) com critérios obrigatórios específicos (BRASIL, 2010).

Em síntese, destaca-se a necessidade de se evidenciar a viabilidade de uso e performance nacional do sistema construtivo em concreto frente às normas. Este trabalho busca diagnosticar o desempenho térmico da envoltória de uma habitação multifamiliar neste sistema. A análise limita-se ao método prescritivo da NBR 15.220, NBR 15.575, RTQ-R e Selo Casa Azul. Serão considerados os requisitos referentes à transmitância de paredes e coberturas, ventilação natural e cruzada e iluminação natural. Será analisada, ainda, a aplicabilidade das prescrições normativas, variações no projeto da habitação e também classificação de uma unidade pelo RTQ-R.

\section{METODOLOGIA}

Definiu-se amostra da tipologia típica de apartamento em paredes de concreto dentro dos parâmetros do mercado. Posteriormente, aplicou-se o método prescritivo de modo a analisar a envoltória do sistema de acordo com a norma NBR 15.220, NBR 15.575, RTQR e Selo Casa Azul. Para o RTQ-R realizou-se classificação da unidade habitacional com as condições mais críticas do ponto de vista térmico. Analisou-se a habitação tal como foi planejada no projeto original bem como uma opção modificada. Considerou-se para esta segunda alternativa o aumento da área de ventilação para os ambientes que não atingiram o mínimo exigido bem como a influência do isolamento de uma manta de lã de vidro de $6 \mathrm{~cm}$ na cobertura para o desempenho da edificação. Para a classificação no RTQ-R adicionaram-se também venezianas nos dormitórios.

\subsection{O estudo de caso}

O caso escolhido consiste num projeto de padrão construtivo popular, fornecido por construtora de abrangência nacional, estruturado em paredes de concreto moldada in loco com $10 \mathrm{~cm}$. Este padrão está sendo atualmente construído, em larga escala, nas zonas climáticas 3 e 8 , para empreendimentos econômicos desta construtora. Conforme se observa na figura 1, a planta da habitação se apresenta em forma de " $\mathrm{H}$ ", tendo a edificação quatro pavimentos e quatro apartamentos por andar com $40 \mathrm{~m}^{2}$. Cada unidade possui sala, dois quartos, banheiro e cozinha conjugada com a área de serviço. A cobertura é composta por laje de concreto de $10 \mathrm{~cm}$ com telha de fibrocimento de $6 \mathrm{~mm}$. Os ambientes não possuem forro e o pé direito é de $2,50 \mathrm{~m}$. As janelas especificadas são compostas por esquadrias de alumínio com vidro simples incolor, sem veneziana.

\section{Figura 1 - Planta base do edifício selecionado.}

\section{Figura 2 e 3 - Fachada 1 e 5, respectivamente, do edifício a ser estudado.}

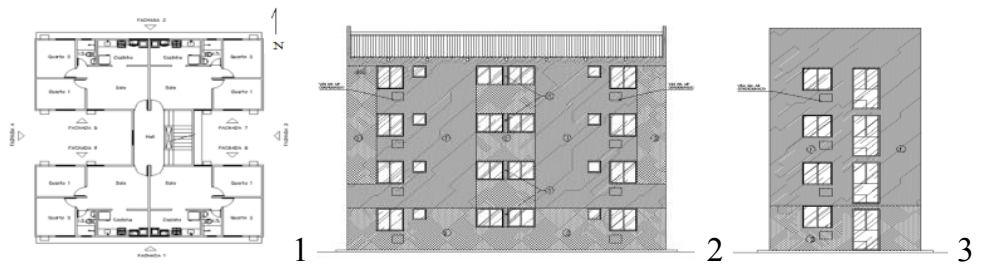

Fonte: Arquivo disponibilizado pela construtora. 


\section{DESENVOLVIMENTO}

Neste item serão expostos os resultados do projeto real e modificado da habitação analisada frente aos limites exigidos para transmitância de paredes e coberturas, ventilação natural e cruzada e iluminação natural da NBR 15.220, NBR 15.575, RTQ-R e Selo Casa Azul. Complementarmente será realizada classificação pelo método prescritivo do RTQ-R da unidade mais crítica do ponto de vista térmico, no caso a 401.

\subsection{Caracterização do desempenho térmico pelas normas.}

Para caracterizar o desempenho térmico da edificação foram analisados os pré-requisitos da envoltória. Todos estes elementos, caso não sejam adequadamente dimensionados, podem influenciar no ganho de calor do edifício. Neste sentido, será inicialmente apresentado o comparativo do projeto real e modificado da habitação com os parâmetros de transmitância térmica de paredes para as zonas bioclimáticas (ZB) brasileiras, definidas na NBR 15.220, conforme a Tabela 1 a seguir.

\section{Tabela 1 - Transmitância térmica de paredes - Upar $\left(\mathbf{W} /\left(\mathbf{m}^{2} \mathbf{K}\right)\right)$.}

\begin{tabular}{|c|c|c|c|c|}
\hline \multicolumn{2}{|c|}{ Norma/Limites para Upar $\left[w^{2} m^{2} \mathrm{k} /\right.$ Zneamento } & ZB1 e ZB2 & $\begin{array}{l}\text { ZB3, ZB5 e } \\
\text { ZB8 }\end{array}$ & $\begin{array}{c}\text { ZB4, ZB6 e } \\
\text { ZB7 }\end{array}$ \\
\hline \multirow{2}{*}{$\begin{array}{l}\text { RTQ-R, } 15.575-4 \mathrm{e} \\
\text { Selo Casa Azul }\end{array}$} & sem exigência de $\alpha$ e CT $2130^{*}$ & $\leq 2,50$ & & \\
\hline & $(\alpha \leq 0,6)$ e $C T \geq 130^{*}$ & & \multicolumn{2}{|c|}{$\frac{1,70}{53,70}$} \\
\hline $15.220-3$ & sem exigência de $\alpha$ e CT & $\leq 3,00$ & $\leq 3,60$ & $\leq 2,20$ \\
\hline $\begin{array}{c}\text { Desempenho UH } \\
(\alpha=0,6)\end{array}$ & real e modificada (tipologia padrão) & 4,09 & 4,09 & 4,09 \\
\hline
\end{tabular}

Legenda:

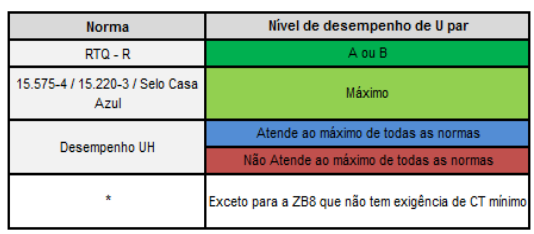

Fonte: (ABNT, 2005; ABNT, 2013; BRASIL, 2010 e BRASIL, 2012). Elaboração própria.

Nota-se que as paredes do projeto real e modificado são equivalentes tendo, portanto, o mesmo valor de transmitância térmica. Em ambas os valores atingidos não foram aprovados em nenhuma norma e ZB. Se faz necessário, portanto, o isolamento térmico das paredes ou a verificação do desempenho térmico do edifício por meio de simulação computacional ou medição, conforme recomendação da NBR 15.575. Todavia, um único parâmetro não pode ser considerado o causador do desempenho inadequado da edificação sendo necessário verificar também, a influência da alteração de outras variáveis. É possível que este sistema construtivo seja passível de execução em conformidade com as normas para todas as ZBs com pequenas modificações. Manteve-se a mesma tipologia de parede para que pudesse ser verificada a influência das alterações na transmitância da cobertura e área de abertura de ventilação. Todavia, estas modificações só poderão ser percebidas na classificação da unidade habitacional a ser realizada pelo RTQ-R. Em relação aos parâmetros de transmitância térmica de coberturas, assim como exigido para paredes, tem-se a Tabela 2 a seguir.

Tabela 2 - Transmitância térmica de coberturas - $U$ cob $\left(W /\left(\mathbf{m}^{2} \mathbf{K}\right)\right)$.

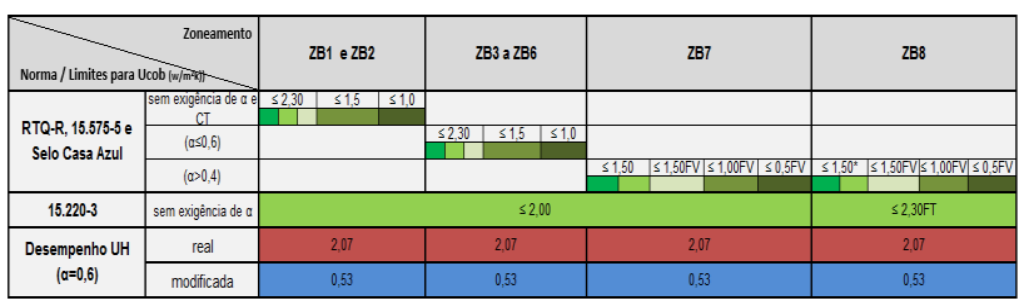

Legenda:

Fonte: (ABNT, 2005; ABNT, 2013; BRASIL, 2010 e BRASIL, 2012). Elaboração própria. 
A cobertura do projeto real composta de laje maciça de concreto $(10 \mathrm{~cm})$, câmara de ar e telha de fibrocimento $(6 \mathrm{~mm})$ atingiu um valor de transmitância térmica que atendeu ao mínimo do RTQ-R, NBR 15.575 e Selo Casa Azul para as zonas bioclimáticas 1 a 6 e também à NBR 15.220 para a zona 8. Caso possuísse cor clara este mesmo sistema atenderia todas as normas e zonas, exceto para a NBR 15.220 por uma diferença de $0,07 \mathrm{~W} /\left(\mathrm{m}^{2} \mathrm{~K}\right)$ nas zonas de 1 a 7 . Todavia este montante não representa uma diferença significativa que justificaria alteração da tipologia ou isolamento do sistema. A cobertura original se mostra, portanto, adequada às exigências das normas, exceto para as zonas 7 e 8. Todavia, a NBR 15.220-3 sugere que para as zonas 1 a 6 se utilize coberturas leves e isoladas e por esta razão testou-se uma opção de isolamento para a cobertura no projeto modificado mantendo a composição original acrescida de uma manta de lã de vidro de 6 $\mathrm{cm}$. Esta alternativa atendeu com facilidade o parâmetro mínimo de todas as normas tendo também alcançado desempenho intermediário para as zonas 3 a 8 e superior nas zonas 1 , 2 conforme valores estabelecidos na NBR 15.575-5. Destaca-se que a diferença para se obter o nível superior nas zonas 3 a 8 foi de $0,03 \mathrm{~W} /\left(\mathrm{m}^{2} \mathrm{~K}\right)$ fato que indica uma diferença ínfima para se atingir o melhor padrão de exigência da NBR 15.575-5. Note-se que para esta cobertura com telha de cor média o valor mínimo exigido pelas normas foi semelhante para todas as zonas bioclimáticas, exceto para NBR 15.220-3 que não considera variações da sua exigência em relação a um limite de absortância. Ademais, da mesma forma que ocorre para as paredes, as zonas 1 e 2, correspondentes a climas mais frios não possuem limites mínimos de absortância em nenhuma das normas analisadas. Em relação ao parâmetro de ventilação natural, apenas para a sala adotaram-se dois diferentes percentuais de abertura para ventilação em relação à área de piso do ambiente. No projeto original em razão de duas partes fixas na janela este valor foi de $5,47 \%$ e no projeto modificado de $15,28 \%$ devido à alteração de follas fixas para o sistema se abrir horizontalmente (pivotante). Desta forma tem-se na Tabela 3, a seguir, o desempenho das aberturas em relação à ventilação natural da edificação.

\section{Tabela 3 - Ventilação natural.}

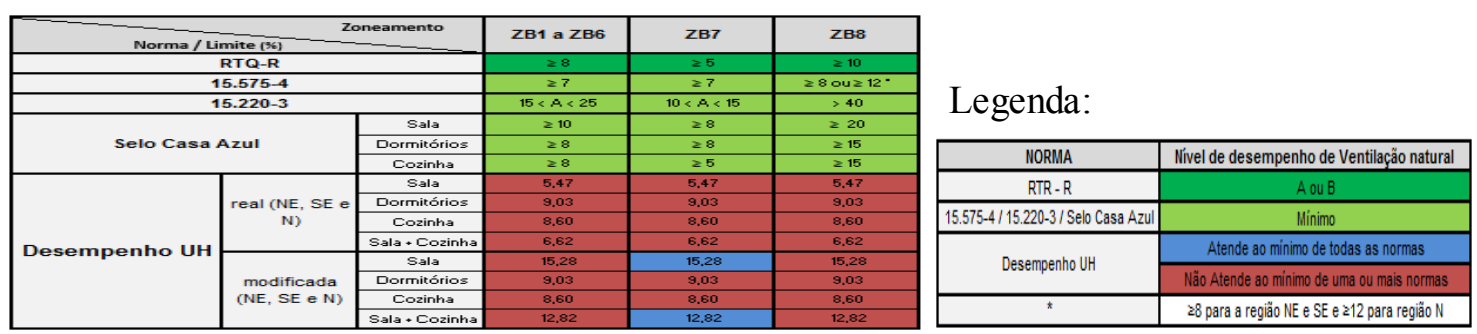

Fonte: (ABNT, 2005; ABNT, 2013; BRASIL, 2010 e BRASIL, 2012). Elaboração própria.

No projeto original, tanto a sala individualizada da cozinha quanto conjugada a esta não atendem a exigência mínima de das normas analisadas à exceção do RTQ-R para zona 7. Já o projeto modificado não atende aos requisitos da NBR 15.220-3 para a zona 1 a 6 e 8 , sendo está última zona em desconformidade também com as prescrições do Selo Casa Azul. O dormitório e a cozinha não cumpriram as áreas mínimas de abertura para a NBR 15.220-3 para nenhuma zona, nem para o RTQ-R ou para o Selo Casa Azul para a zona 8 tanto para o projeto real quanto para o modificado na Região Nordeste e Sudeste e nenhuma norma na Região Norte desta mesma zona. Nota-se, no geral um maior rigor nas exigências da NBR 15.220-3 para todas as zonas bioclimáticas, especialmente para a zona 8. Esta divergência dificulta a aplicabilidade das normas de forma padronizada e os limites mais rigorosos são de difícil cumprimento na prática, já que para atendimento os 
vão deveriam aumentar 25 a $30 \%$ nos ambientes do projeto modificado, o que corresponderia a 66 e $63 \%$ da área da parede em que estão inseridas para a cozinha e para sala, respectivamente, considerando uma área livre de $1,2 \mathrm{~m}$ para peitoril apenas para a cozinha. Portanto, caso fosse possível uniformizar as exigências relativas à ventilação natural em relação ao valor predominante médio das prescrições, excluindo os valores mais rigorosos da NBR 15.220-3 e Selo Casa Azul para zona 8, a edificação modificada atingiria o mínimo requerido. Em relação aos parâmetros de ventilação cruzada, tem-se a recomendação da ventilação seletiva, cruzada e cruzada permanente conforme se observa na Tabela 4 a seguir.

Tabela 4 - Ventilação cruzada.

\begin{tabular}{|c|c|c|c|c|}
\hline Zorma / Limite & ZB1 & ZB2, ZB3 E ZB5 & ZB4, ZB6 E ZB7 & ZB8 \\
\hline RTQ-R & & 20,25 & 20,25 & 20,25 \\
\hline $15.575-4$ & & & & \\
\hline $15.220-3 /$ Selo Casa Azul & & & & \\
\hline Desempenho UH (real) & & & & \\
\hline
\end{tabular}

Legenda:

Fonte: (ABNT, 2005; ABNT, 2013; BRASIL, 2010 e BRASIL, 2012). Elaboração própria.

Observa-se que a edificação original não precisou ser modificada neste requisito pois cumpriu a exigência apresentada para todas as normas. Nota-se que NBR 15.575-4 não possui exigência para o parâmetro de ventilação cruzada. Já o RTQ-R apresenta prescrição de teor diferente em relação às demais. Assim, a uniformidade das exigências simplificaria a aplicabilidade das normas em relação a este parâmetro. Por fim, quanto à iluminação natural tem-se a síntese representada na Tabela 5 a seguir.

Tabela 5 - Iluminação natural.

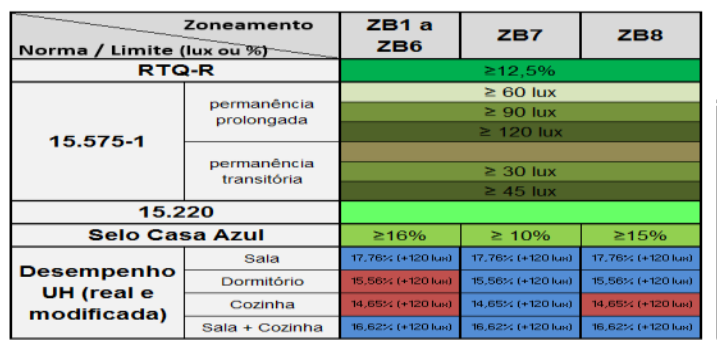

Legenda:

\begin{tabular}{|c|c|c|c|c|}
\hline Normas & \multicolumn{4}{|c|}{ Nivel de desempenho e exigéncia minima } \\
\hline 15.220 & \multicolumn{4}{|c|}{ Sem exighencia } \\
\hline RTQ-R & \multicolumn{4}{|c|}{ Aou $B$} \\
\hline $15.575-1$ & Minimo näo requerido & Minimo & Intemediditio & Superior \\
\hline Selo Casa Azul & \multicolumn{4}{|c|}{ Minimo } \\
\hline \multirow{2}{*}{ Desempenho UH } & \multicolumn{4}{|c|}{ Atenteg ao minimo de todas as normas } \\
\hline & \multicolumn{4}{|c|}{ 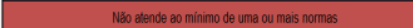 } \\
\hline
\end{tabular}

Fonte: (ABNT, 2005; ABNT, 2013; BRASIL, 2010 e BRASIL, 2012). Elaboração própria.

Neste caso, o projeto real e o modificado não apresentam diferenças em relação à área disponível para iluminação natural. Sendo assim, apenas para o Selo Casa Azul os parâmetros do dormitório e da cozinha não atingiram o mínimo exigido para todas as zonas, exceto para a 7. Nota-se, também, que o Selo Casa Azul apresenta um rigor maior do que as demais normas dificultando sua aplicação. Cabe destacar que a NBR 15.220 não apresenta exigência para este quesito uma vez que trata especificamente de desempenho térmico. Observa-se, também que a NBR 15.575-1 estabelece parâmetros para este quesito em nível de iluminação ou iluminância (lux) o que dificulta uma avaliação uniforme das exigências normativas uma vez que as demais apresentam um percentual mínimo de aberturas em relação à área útil do ambiente. Para avaliação das prescrições da NBR 15.575 fez-se uma simulação anual dos ambientes da edificação, para o horário das $6 \mathrm{~h}$ às $18 \mathrm{~h}$, no programa Daysim com objetivo de verificar os níveis de 
iluminância atingidos. Contudo, tal norma não específica o valor médio de atendimento deste parâmetro ao longo do dia. Assim, estabeleceu-se um aproveitamento de $70 \%$ da exigência ao longo do dia tanto para os ambientes de permanência prolongada quanto para os e permanência transitória. Assim, conforme a norma selecionada a edificação pode atender ou não ao mínimo exigido já que não existe uma similaridade nas prescrições (FERREIRA; PEREIRA, 2012).

\subsection{Classificação da envoltória do edifício pelo RTQ-R.}

Para a classificação do edifício em estudo pelo método prescritivo do RTQ-R considerouse a unidade habitacional que apresentasse as condições mais críticas do ponto de vista térmico. Desta forma, examinou-se o apartamento de cobertura $\mathrm{n}^{\mathrm{o}} 401$ sendo o quarto 1 com uma face voltada para sul e outra para oeste, o quarto 2 orientado para norte e oeste e a sala voltada para sul. Avaliou-se a habitação para as condições do projeto original e modificado. Na tabela 6, a seguir, tem-se a classificação da unidade para o projeto real. Cabe ressaltar que a avaliação baseia-se numa classificação variável de $\mathrm{A}$ ao $\mathrm{E}$, respectivamente da melhor para a pior, mediante uma pontuação calculada a partir dos níveis de eficiência dos diferentes requisitos conforme equações específicas e equivalentes numéricos para as condições de verão e inverno. Os Graus Hora de Resfriamento (GHR) e o Consumo de Aquecimento (CA) apresentam pesos diferenciados para cada zona bioclimática sendo este último aplicável somente para as zonas mais frias enumeradas de 1 a 4.

Tabela 6 - Classificação da UH do projeto real.

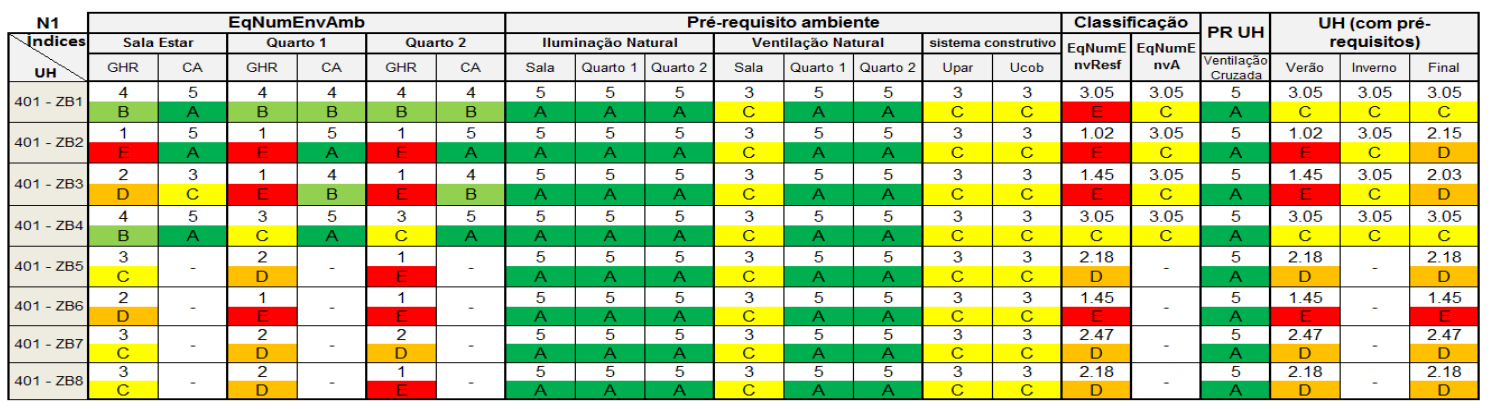

Fonte: (BRASIL, 2012). Elaboração própria.

Em relação aos pré-requisitos, a edificação obteve classificação A para a iluminação natural de todos os ambientes e a ventilação natural obteve A para os quartos e $\mathrm{C}$ para a sala tendo em vista a reduzida área de abertura em razão de uma grande área fixa especificada no projeto. O sistema construtivo obteve classe $\mathrm{C}$ conforme os valores de transmitância térmica das paredes e cobertura adotadas. A ventilação cruzada atende ao pré-requisito da unidade habitacional atingindo a classificação $\mathrm{A}$.

Quanto ao GHR observa-se uma variação de B a E sendo a zona 1 aquela que apresentou melhor classificação possui, de fato, as temperaturas mais amenas no verão. A pior classificação se deu para a zona 2 na qual todos os ambientes atingiram a classe E. Esperava-se que as zonas de 5 a 8, que apresentam, no geral, climas mais quentes, tivessem piores classificação para o GHR. A sala por estar orientada a sul deveria também apresentar melhor classificação do que os outros ambientes fato que não se confirmou nas zonas 1 e 2 . O quarto 2 por estar voltado para norte e oeste deveria ter a pior classificação mas somente nas zonas 5 e 8 esta influência da orientação pôde ser observada. 
Quanto ao CA esperava-se que a zona 1, região de inverno mais acentuado, tivesse a pior classificação para o consumo de aquecimento o que não se confirmou uma vez que a zona 3 obteve a classificação mais baixa. O melhor resultado de CA foi para as zonas 2 e 4 . Era de se esperar que a zona 4, de clima quente e seco, tivesse melhor consumo de aquecimento já que não apresenta uma grande frequência de ocorrência de baixas temperaturas. Por outro lado, a zona 2 deveria ter apresentado pior CA do que a Zona 3. Recomenda-se que as zonas 2 e 3 sejam simuladas computacionalmente para verificar possíveis diferenças na avaliação do método prescritivo do RTQ-R. No geral, observa-se que o desempenho do sistema construtivo no verão foi regular na zona 1 e 4 (C), insuficiente nas zonas 5, 7 e 8 (D) e inadequado nas zonas 2, 3 e 6 (E). No inverno o desempenho foi igualmente admissível (C) nas zonas de 1 a 4 . Nota-se que a edificação só teria um desempenho minimamente aceitável nas zonas 1 e 4 . Infere-se que esta tipologia necessita de ajustes para melhorar seu desempenho térmico.

$\mathrm{Na}$ tabela 7 a seguir, tem-se a classificação da unidade habitacional conforme modificações no projeto. Para esta tipologia acrescentou-se veneziana nos dormitórios, aumentou-se a área de ventilação na sala de 5,47\% para $15,28 \%$ e acrescentou-se isolamento na cobertura obtendo-se, portanto, a classe A nestes pré-requisitos.

Tabela 7 - Classificação da UH do projeto modificado.

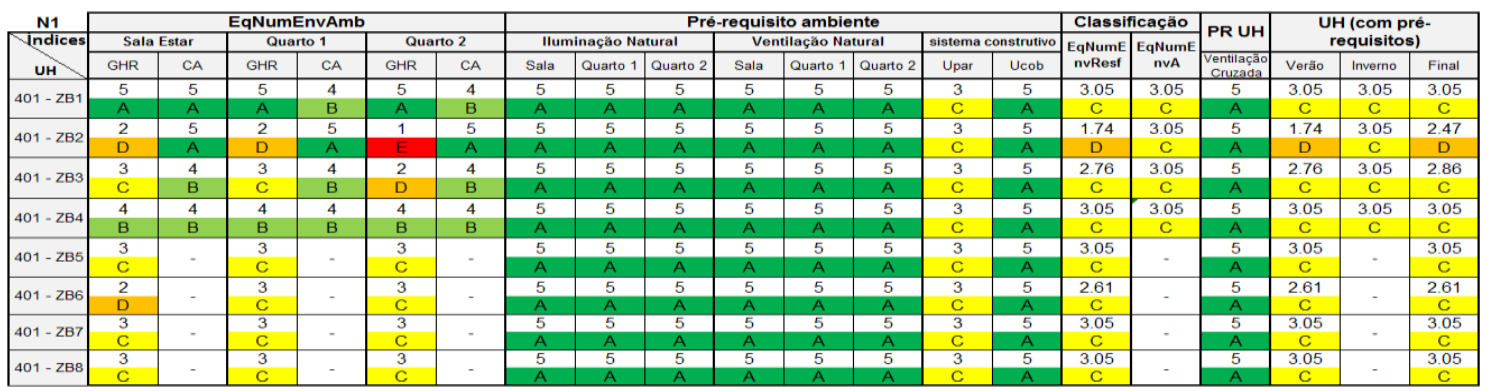

Fonte: (BRASIL, 2012). Elaboração própria.

Acreditava-se que a cobertura original não aprovada pelas prescrições estivesse impactando negativamente no desempenho global do sistema. De fato, a variável que apresentou maior influência na classificação foi à redução da transmitância térmica da cobertura. A alteração da área de ventilação na sala não influenciou a classificação para o GHR e o CA entrando apenas para a média do equivalente numérico de resfriamento e aquecimento. $\mathrm{O}$ impacto da adoção do sombreamento pelas venezianas nos quartos também não pode ser percebido. Esperava-se a tipologia com paredes de concreto maciças atingisse uma classificação melhor para todas as zonas após os ajustes na ventilação insuficiente da sala e também do isolamento da cobertura em relação ao projeto original. Observa-se significativa melhoria nos GHR e no CA, porém, as zonas 2 e 3 mantiveram uma das piores classificações para o GHR. Percebe-se que apesar da parede de concreto não ser previamente aprovada pelas prescrições normativas (NBR 15.220, NBR 15.575, Selo Casa Azul e RTQ-R) obteve-se uma classificação regular da unidade habitacional com as condições térmicas mais críticas da edificação em todas as zonas bioclimáticas brasileiras, exceto para a zona 2 no verão. O projeto modificado apresentou relevante melhoria em relação ao desempenho daquele originalmente concebido. Cabe destacar que a classificação da unidade 401 seria, em tese, a pior do edificio uma vez que os dormitórios estão voltados para a direção norte e oeste, sendo as fachadas que recebem maior carga térmica. Assim, os apartamentos dos andares de 1 a 3 e mesmo as outras 
unidades do quarto andar, poderão ter um desempenho melhor do que este ora apresentado. Após os resultados da tipologia modificada, testou-se, complementarmente, o potencial de melhoria na classificação da variação da absortância solar da cobertura, capacidade térmica do sistema construtivo e transmitância das paredes. Verificou-se que a redução da absortância da cobertura isolada poderia contribuir para reduzir o GHR do sistema construtivo, mas por outro lado aumentaria o consumo anual necessário para aquecimento (CA), em alguns casos. Esta diferença, contudo, não significou na maioria dos casos variação na classificação do edifício. Já o aumento da capacidade térmica e a redução da transmitância térmica da parede não teria um impacto significativo na classificação final da unidade habitacional conforme variações testadas para o sistema. Assim, o uso da cor clara na cobertura seria mais econômico para melhorar a classificação da habitação do que o isolamento da cobertura pelo método prescritivo. Ademais, poderiam ser adotadas estratégias de melhoria no edificio ${ }^{1}$ de forma a contabilizar pontos extras para aumentar ainda mais a classificação final. De toda forma, para resultados mais detalhados recomenda-se simulação computacional do caso estudado.

\section{CONSIDERAÇÕES FINAIS}

No Brasil a adoção de uma norma pode ou não indicar a aprovação de determinado requisito necessário para avaliação do desempenho térmico de uma envoltória. Neste sentido, é necessario que haja uniformização das exigências normativas. Em função da norma selecionada verifica-se aumento de rigor dos parâmetros em relação às demais por vezes inclusive dificultando sua aplicabilidade, principalmente o quesito de ventilação natural. Percebe-se, portanto uma necessidade de atualização dos valores limites das normas para estabelecimento de um mínimo comum, especialmente para a NBR 15.2203, que apresenta valores de transmitância térmica, e área de abertura diferentes das demais normas que desde 2005 não passou por modificações.

No geral, após modificações no projeto foi possível atingir um desempenho regular para o verão e inverno para a unidade habitacional com as condições térmicas mais críticas, exceto para a zona 2. Para a tipologia analisada, caso a cobertura se apresentasse em cor clara seu isolamento seria desnecessário para o atendimento do limite estabelecido pela NBR 15.575, RTQ-R e Selo Casa Azul, para as zonas 3 a 8 que consideram um valor de transmitância térmica menor em razão da adoção do limite de absortância solar $(\alpha)$ mais baixo. Todavia, a melhoria da transmitância térmica da cobertura causou significativo incremento da eficiência do sistema como um todo para a classificação estabelecida pelo RTQ-R. O desempenho do edifício está diretamente atrelado às escolhas projetuais e suas variáveis. Assim, uma única variável não responde isoladamente pelo seu desempenho inadequado da edificação. As normas NBR 15.575 e RTQ-R abrem, ainda, a possibilidade de adotar procedimentos para um diagnóstico mais aprofundado do edifício por meio de simulação computacional, caso algum requisito não tenha atendido as prescrições estabelecidas.

Este trabalho buscou diagnosticar o desempenho do sistema construtivo em concreto maciço no Brasil para a tipologia padrão adotada em habitações multifamiliares de interesse social. Por meio deste estudo de caso testou-se, também, a similaridade das exigências normativas para os requisitos comuns estabelecidos, bem como a aplicabilidade de seus limites na prática. Apenas pelo método prescritivo do RTQ-R é possível atingir um desempenho aceitável para as paredes de concreto, mesmo seu valor

\footnotetext{
${ }^{1}$ Podem-se citar, neste caso, as iniciativas que racionalizam o uso da água e energia, dentre outras.
} 
de transmitância térmica sendo superior ao limite estabelecido. Para a NBR 15.575 devese testar o desempenho do edificio pelo método de medição ou simulação computacional.

Conforme classificação realizada pelo RTQ-R, o sistema construtivo em concreto maciço se mostrou uma opção viável do ponto de vista térmico para os empreendimentos econômicos com reduzidos prazos de execução para todas as zonas bioclimáticas brasileiras. Todavia, deve-se atentar para os ajustes necessários para cada especificidade climática em especial para a zona 2 que apresentou desempenho insuficiente para esta tipologia. A absortância reduzida na cobertura se mostrou a alteração mais significativa para a melhoria da eficiência da envoltória. Assim, não existe um fator isolado para um desempenho térmico inadequado. Deve-se avaliar a edificação como um todo, incluindo estratégias projetuais de orientação, dimensionamento de aberturas, dentre outras.

\section{AGRADECIMENTOS}

Os autores agradecem à ELETROBRAS pelos recursos financeiros aplicados no financiamento do projeto junto a R3E que possibilitou o desenvolvimento de uma tese de doutorado junto à Engenharia de Estruturas da UFMG bem como o apoio financeiro da Fundação de Amparo à Pesquisa do Estado de Minas Gerais - FAPEMIG.

\section{REFERÊNCIAS}

ABNT - ASSOCIAÇÃO BRASILEIRA DE NORMAS TÉCNICAS. NBR 15.220: Desempenho térmico de edificações. Rio de Janeiro, 2005.

habitacionais - Desempenho. Rio de Janeiro, 2013. . NBR 15.575: Edifícios

BRASIL - CEF - Caixa Econômica Federal. JOHN, Vanderley Moacyr; PRADO, Racine Tadeu Araújo (Coordenadores). Selo Casa Azul: Boas práticas para habitação mais sustentável. São Paulo: Páginas \& Letras - Editora e Gráfica, 2010.

BRASIL - INMETRO - Instituto Nacional de Metrologia. Regulamento Técnico da Qualidade para o nível de eficiência energética de Edificações Residenciais - RTQ-R. Rio de Janeiro, 2012.

BRASIL - Ministérios das Cidades - Secretaria Nacional de Habitação. Déficit Habitacional no Brasil 2008 com dados de 2007 reponderados. Brasília, [2008]. Disponível em: http://www.cidades.gov.br/index.php?option=com_content\&view $=$ article\& $\mathrm{id}=1100 \& I t e m i d=19$

2. Acesso em 30 abr. 2013.

FERREIRA, Camila Carvalho; PEREIRA, Iraci Miranda. Avaliação de desempenho térmico de habitação de interesse social de acordo com a NBR 15.575, para as diversas zonas bioclimáticas. XIV ENTAC - Encontro Nacional de Tecnologia do Ambiente Construído, p. 3590-3595. Juiz de Fora, out. 2012.

MELHADO, Silvio Burrattino; BARROS, Mercia Maria S. Bottura. Recomendações para a produção de estruturas de concreto armado em edifícios. São Paulo: Projeto EPUSP/SENAI, 1998. 